\title{
JIHAD DALAM LITERATUR PESANTREN SALAF
}

\author{
Rustam Ibrahim \\ UNU Surakarta \\ rustam@yahoo.com
}

Artikel ini menyoroti peran pesantren dalam memahami jihad, yang lebih diprioritaskan pada dunia pendidikan, karena pendidikan dianggap lebih efektif dan menjanjikan dalam mempersiapkan generasi masa depan dalam menyebarkan agama Islam. Terbukti, sejak zaman penjajahan sampai sekarang, kiprah pesantren sangat besar dalam sejarah pendidikan di Indonesia. Banyak alumni-alumni pesantren yang telah berhasil menyebarluaskan ajaran Islam melalui pendidikan, disamping juga berhasil mempertahankan eksistensi akidah Islam dari rongrongan para penjajah.

Kata Kunci: Jihad, Literatur, Pesantren Salaf

\section{PENDAHULUAN}

Aksi teroris yang sedang marak dilakukan oleh sebagian kelompok Islam radikal saat ini menjadi sebuah momok yang menakutkan bagi setiap orang. Kondisi yang sebelumnya aman dan damai tiba-tiba berubah menjadi tegang dan kacau ketika terdengar aksi teroris yang kebanyakan menggunakan bom sebagai media aksinya. Bahkan tindakan teroris mulai berkembang dengan pelatihan militer di berbagai daerah, menjadikan perampokan sebagai sumber dana operasional, dan berbagai kejahatan lainnya. Ironisnya mereka membungkus aksi mereka dengan menggunakan dalil-dalil Islam sebagai dasar pijakan aksi mereka. Para teroris melakukan aksi bom bunuh diri dengan mengatasnamakan jihad, menghalalkan perampokan dengan dalih harta fai', menganggap aparat pemerintah sebagai antek orang kafir, dan kejahatan-kejahatan lainnya yang mereka anggap sebagai kebenaran. Yang paling mengherankan, sebagian dari mereka adalah lulusan pesantren, hal ini tentunya berimbas pada pesantren, terutama asumsi publik yang mengkaitkan ajaran teroris dengan ajaran pesantren, khususnya mengenai masalah jihad. Akhirnya publik banyak yang bertanyatanya: apakah pesantren menjadi sarang teroris?

Perlu ada penelusuran terhadap ajaran pesantren khususnya mengenai

TEOLOGIA, VOLUME 23, NOMOR 1, JANUARI 2012 
makna jihad sehingga dapat terkuak apakah pesantren mengajarkan terorisme. Oleh karena itu, penulis berusaha menelusuri terhadap literatur yang dipakai pesantren khususnya dalam masalah jihad. Literatur-literatur yang banyak digunakan antara lain: ${ }^{1}$ Kitab Fiqih mengacu pada Kitab Fiqh al-Islami karya Dr. Wahbah Zuhaili, Fathu al-Mu'in, dan Fathu al-Qorib. Kitab Tafsir mengacu pada Tafsir Jalalain karya Jalauddin al-Suyuthi dan Jalaluddin al-Mahalli, juga pada tafsir al-Qurtubi, Kitab akhlak/tasawuf mengacu pada kitab Ihya' Ulum ad-Dien Karya Imam Al-Ghazali, dan kitab Hadits mengacu pada kitab Bukhori Muslim.

\section{PENGERTIAN JIHAD}

Secara leksikal, jihad diartikan sebagai "upaya keras", "perjuangan mati-matian", atau dalam bahasa Jawa disebut usaha "pol-polan" untuk melawan sesuatu yang salah. Sedangkan jihad secara terminologis, menurut Mustofa Al-Khin, adalah "mencurahkan kemampuan untuk menegakkan agama, menjunjung tinggi kalimat Allah, dan membumikan syari'at-Nya". Sementara menurut Wahbah Zuhaili, jihad merupakan "upaya pencurahan tenaga secara fisik yang diproyeksikan untuk mengimplementasikan pesanpesan Tuhan di muka bumi guna mengaktualisasikan tugas-tugas manusia sebagai khalifah-Nya. ${ }^{2}$

Berdasarkan defenisi di atas, maka jihad dalam istilah syariat ${ }^{3}$ dapat dimaknai sebagai perjuangan (bukan hanya peperangan) untuk menegakan kebenaran dalam menjunjung tinggi agama Islam. Jadi apapun bentuknya, perjuangan yang dilandasi dengan tujuan untuk menegakan kebenaran agama, itu dinamakan jihad. Namun pengaplikasiannya tentu harus melalui prosedur dan fase-fase yang sudah digariskan oleh syariat. Artinya, dalam tataran praktis, syariat telah menentukan bentuk-bentuk jihad dalam berbagai medan perjuangan. Tidak semua tindakan dapat dikatakan sebagai jihad jika tidak memenuhi prosedur atau kriteria yang telah ditentukan syariat. Perang melawan orang kafir dengan mengangkat senjata, misalnya, hanya merupakan salah satu (dan bukan satu-satunya) media untuk berjihad. Dan kitab-kitab fiqh di sejumlah pesantren banyak sekali yang membahas khusus tentang masalah ini.

\section{CAKUPAN MAKNA JIHAD}

Dalam literatur-literatur Pesantren, istilah "jihad" memiliki cakupan makna yang sangat komprehensif; pertama, mujahadah, yaitu perang spiritual melawan hawa nafsu; ${ }^{4}$ kedua, ijtihad, yaitu mencurahkan 
kemampuan guna mencetuskan hukum (Islam) melalui metode yang ketat, dan diproyeksikan untuk mencetuskan pendapat independen dalam yurisprudensi Islam dengan metode analogi (qiyas) melalui fondasi ratiolegis (ilat) yang terpetik dari Al-Qur'an dan Hadits; ${ }^{5}$ ketiga, amar ma'ruf nahi munkar, perjuangan menciptakan lingkungan sosial yang memungkinkan kaum Muslimin untuk mengimplementasikan kewajibankewajiban syariat, serta menyesuaikan dengan norma-norma etiknya, ${ }^{6}$ keempat, qital $f i$ sabil Allah, perang untuk membela agama dari sesuatu yang mengancamnya dengan kode etik yang telah dijelaskan al-Quran dan Hadits. $^{7}$

Mujahadah adalah fase yang paling berat. Perjuangan mujahadah di samping bersifat individual dalam menghadapi hawa nafsu, juga limit perjuangan itu bersifat kontinue sepanjang masa. Diceritakan, ketika Rasulullah SAW. kembali pulang dari Perang Badar, para sahabat banyak yang bangga dengan kemenangan yang telah mereka raih, karena dengan jumlah yang sedikit, mereka mampu mengalahkan musuh yang jumlahnya berlipat ganda. Tetapi Rasulullah SAW. mengingatkan para sahabat:

$$
\text { رجعنا من الجهاد الأصغر الى الجهاد الاكبر رواه ابن ماجه }
$$

"Kita kembali dari peperangan yang kecil menuju peperangan yang lebih besar. "(HR. Ibnu Majah). ${ }^{8}$

Peperangan yang lebih besar yang dimaksud Rasul SAW. dalam hadits di atas tidak lain adalah peperangan melawan hawa nafsu (mujahadah). Inilah jihad yang paling besar dan berat dalam pandangan Islam.

\section{FASE-FASE JIHAD}

Jika ditelusuri secara historis, jihad dalam lanskap qital fi sabil Allah diinstruksikan secara gradual (bertahap). Metode tersebut merupakan salah satu wahana dakwah Islam yang acap kali mewarnai turunnya al-Qur'an. Hal ini didasarkan pada kondisi sosial masyarakat awal Islam yang sedang mengalami transisi kepercayaan dari dinamisme, animisme, dan politeisme, menuju ajaran monoteisme (Tauhid), sehingga di pandang perlu dilakukan upaya afirmasi hukum secara bertahap. Fase-fase tersebut adalah; (1) defensif atau bertahan, (2) izin atau pemberian kewenangan dari Allah untuk mengangkat senjata sesuai tuntutan situasi dan kondisi, dan (3) offensif atau fase penyerangan. 


\section{Fase Defensif}

Pada saat Nabi SAW. pertama kali mengembangkan dakwah Islamiahnya, reaksi keras dan penentangan datang bertubi-tubi dari para penguasa Makkah yang tidak ingin posisinya terganggu oleh ajaran Nabi SAW. ${ }^{9}$ Pada mulanya mereka berusaha melakukan upaya diplomatik dan persuasif, namun tetap gagal menghentikan dakwah Nabi, sehigga akhirnya mereka mulai menggunakan cara-cara kekerasan secara fisik. ${ }^{10}$ Kaum Muslimin yang saat itu masih berjumlah sedikit ditekan habis-habisan dengan perlakuan yang tidak manusiawi. Mereka dipukul, dicambuk, tidak diberi makan dan minum, diterlentangkan di atas padang pasir, ditindih dengan batu besar; hampir semua sahabat pernah mendapatkan perlakuan semacam itu. ${ }^{11}$

Salah satu penyiksaan yang sangat kejam dialami oleh Bilal Bin Rabbah dan keluarga Yasir. Di bawah sengatan matahari gurun pasir yang panas membakar, tubuh Bilal bin Rabah dicambuk dan ditindih dengan batu besar oleh majikannya, Umayyah bin Khalaf, selama berhari-hari tanpa diberi makan dan minum. Hal yang tidak jauh berbeda juga dialami oleh Ammar bin Yasir dan istrinya, Sumayyah. ${ }^{12}$

Dalam tahap ini, Allah belum mengizinkan jihad kepada Kaum Muslimin, meskipun penderitaan datang bertubi-tubi. Saat itu, mereka diperintahkan untuk tetap konsisten mendirikan salat, membayar zakat, menjunjung tinggi persamaan derajat, menghindari Non-muslim yang selalu menteror, serta bersabar dan memaafkan atas penindasan yang mereka alami. $^{13}$

Jihad saat itu belum diizinkan oleh Allah Swt, karena disamping Kaum Muslimin berada di Tanah Haram (Mekah), juga karena jumlah mereka masih sangat sedikit. Disamping itu, Allah juga ingin menguji kualitas kesabaran kaum Muslimin dalam menjalankan perintah-Nya; apakah dengan siksaan yang demikian berat itu mereka masih konsisten menjalankan perintah Allah atau tidak ${ }^{14}$

Fase ini disebut tahap kaffu al-yad atau menahan diri (deffensif). ${ }^{15}$ Banyak ayat yang menerangkan fase deffensif ini, seperti dilansir oleh AlQur'an dalam surat al-Baqarah/2:109:

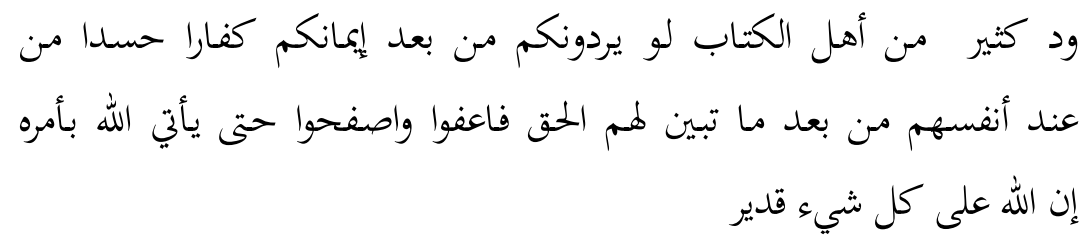


"Sebagian besar ahli kitab menginginkan agar mereka dapat mengembalikan kamu kepada kekufuran setelah kamu beriman, karena dengki yang timbul dari diri mereka, setelah nyata bagi mereka kebenaran. Maka maafkanlah dan biarkanlah mereka, sampai Allah mendatangkan perintahNya. Sesungguhnya Allah Maha Kuasa atas segala sesuatu" (QS. al-Baqarah/2: 109).

Aplikasi jihad dalam masa ini tidak diperbolehkan menggunakan kekerasan, tapi dengan jalan halus, hal ini didasarkan pada firman Allah Swt.:

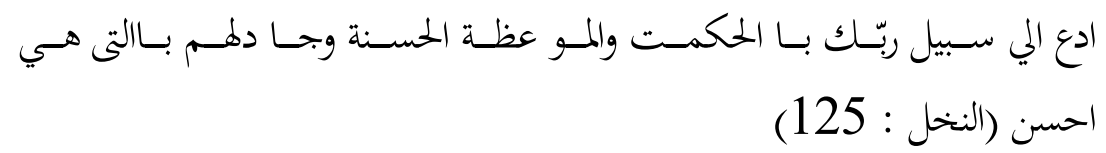

Serulah (manusia) kepada jalan Tuhanmu dengan hikmah dan pelajaran yang baik, dan berbantahlah dengan mereka melalui cara yang lebih baik. (QS. an-Nahl/16: 125) ${ }^{16}$

Dari ayat ini jelas bahwa jihad dengan cara halus merupakan hal yang pertama dilakukan dalam Islam. Dengan ajakan dan syi’ar Islam secara halus, orang lain akan lebih simpati dan tertarik bila ia merasa dihargai. Bahkan ia akan cenderung mengikuti ajakan kita ketika apa yang kita sampaikan merupakan sebuah kebenaran dan dapat diterima akal.

Ayat-ayat lain yang menerangkan fase ini juga bisa dijumpai dalam QS.Al-Nisa' [4]: 77, Al-An'am [6]: 106, Al-Insan [76]: 24, Al-Hijr [15]: 85, Al-Jatsiyah [14]: 45, Qaf [50]; 39, dan Al-Muzzammil [73]: 10. Sedangkan hadits-hadits yang menerangkan fase ini jumlahnya banyak sekali, di antaranya: "Sesungguhnya aku diperintahkan untuk memaafkan, maka janganlah memerangi kaum (yang dzalim) itu."(H.R.Ibnu Hatim dari Ibnu Abbas).

\section{FASE IZIN}

Karena siksaan yang dialami umat Muslim kian hari semakin keterlaluan, akhirnya Nabi Muhammad SAW. mengungsikan para sahabatnya ke luar Makkah. Tempat tujuan pengungsian tersebut adalah Abessinia atau Habasyah (Ethophia). Rombongan yang terdiri dari 10 orang pria dan 5 orang wanita berangkat ke Habasyah, dipimpin oleh Utsman Bin Affan, Zubair Bin Awwam dan Abdurrohman Bin Auf, kemudian disusul oleh rombongan kedua yang di pimpin oleh Ja'far Bin Abu Thalib. Ada yang mengatakan bahwa rombongan ini terdiri dari 73 pria, sumber lain menyebutkan mereka terdiri dari 83 pria dan 11 wanita. ${ }^{17}$ 
Berbagai usaha dilakukan kafir Quraisy untuk menghalangi keberangkatan Kaum Muslimin ke Habasyah, termasuk membujuk raja Habasyah agar menolak kehadiran umat Islam di sana. Namun usaha tersebut gagal total.

Sementara Kaum Muslimin yang masih tinggal di Mekah terus mendapat tekanan yang bertubi-tubi, sehingga mereka mulai tidak sabar dan meminta ijin kepada Nabi untuk berperang melawan mereka. Namun Nabi belum memberikan ijin karena belum ada perintah dari Allah untuk berperang. Perintah untuk mengangkat senjata baru dibolehkan ketika Nabi dan umat Islam telah hijrah ke Madinah, melalui firman Allah Swt: ${ }^{18}$

$$
\begin{aligned}
& \text { أذن للّذ ين يقاتلون بأَهم ظلموا وإن الله على نصرهم لقد ير الذ ين } \\
& \text { أخرجوا من د يارهم بغير حق لنق }
\end{aligned}
$$

"Telah diizinkan berperang bagi orang-orang yang diperangi, karena sesungguhnya mereka telah dianiaya. Dan sesungguhnya Allah benarbenar Maha Kuasa menolong mereka itu. (yaitu) orang-orang yang telah diusir dari kampung halaman mereka tanpa alasan yang benar" ( Q.S. alHajj/22:39-40).

Izin untuk memerangi Kafir Quraisy turun di saat jumlah umat Islam sudah sangat banyak dan memiliki kekuatan yang hampir sepadan dengan Kaum Quraisy. Izin berperang ini dipandang sebagai media untuk mempertahankan diri dari serangan musuh, agar Kaum Muslimin bisa menjalankan aktivitas ibadah sebagaimana mestinya.

Jika dirunut ke belakang, izin berjihad sebenarnya bukan hanya diterima oleh umat Islam saja, melainkan juga diterima oleh para umat sebelum Nabi Muhammad SAW. Pada zaman Nabi Musa as., misalnya, jihad digunakan sebagai media untuk melindungi Gereja. Pada zaman Nabi Isa as., jihad menjadi sarana untuk menjaga shawami'. Sedangkan izin berjihad pada zaman Nabi Muhammad ditujukan untuk melindungi Masjid dari serangan Kafir Quraisy yang terus melakukan intimidasi. ${ }^{19}$ Hal ini tercermin dalam firman Allah Swt:

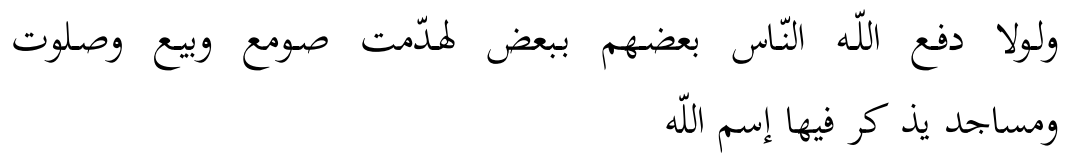

Sekiranya Allah tidak menolak (keganasan) sebagian manusia dengan sebagian yang lain, tentulah telah dirobohkan biara-biara Nasrani, gereja- 
gereja, rumah-rumah ibadat orang Yahudi, dan Masjid-masjid yang di dalamnya banyak disebut nama Allah. (QS. al-Hajj/22: 40).

Artinya, umat Islam saat itu hanya diizinkan berperang, belum diperintahkan untuk melakukan penyerangan ke kawasan musuh (offensif, hujum). ${ }^{21}$ Izin berperang dalam fase ini hanya berlaku ketika kaum Muslimin mendapat agresi dari kaum kafir terlebih dahulu atau hanya sebatas pertahanan. Ayat-ayat lain yang menerangkan fase ini di antaranya; Al-Baqarah/2: 190, dan an-Nisa'/4 : 77.

\section{Fase Offensif}

Pada fase ketiga ini, umat Islam mulai di wajibkan berjihad dan melakukan penyerangan keluar kawasan Muslim (Madinah). Hal ini terpotret dalam firman Allah Swt:

$$
\text { كتب عليكم م القتال وهو كره لكم وعسى أن تكرهوا شيئا وهو خير }
$$

"Diwajibkan atas kamu beperang, padahal berperang itu adalah sesuatu yang kamu benci. Boleh jadi kamu membenci sesuatu padahal itu amat baik bagimu, dan boleh jadi kamu menyukai sesuatu padahal itu amat buruk bagimu; Allah Maha Mengetahui sedang kamu tidak mengetahui. "(QS. Al-Baqarah/2: 216)

Ayat-ayat lain yang menjelaskan tentang kewajiban jihad secara offensif, antara lain adalah; al-Baqarah/2: 244, al-Ma'idah/5: 54, al-Anfa $>1 / 8$ : 6, 8, 39, dan 57, at-Taubat/9: 5, 12, 14, 29, 36, 73, dan 123, serta Muhammad/47: 4 dan 22.

Perintah Allah dengan menggunakan kalimat "kutiba" ini bersifat general-representatif (fardlu kifayah). ${ }^{22}$ Artinya, walaupun objek kewajiban ini berlaku bagi seluruh komunitas Muslim yang memenuhi kriteria sebagai subjek jihad, namun dalam praksisnya cukup dilakukan oleh sebagian kaum Muslimin saja, tidak harus keseluruhan. Jika sebagian Kaum Muslimin telah ada yang melaksanakan perintah penyerangan, maka hal itu sudah mewakili komunitas lain yang tidak melakukannya. Inilah yang dimaksud jihad yang wajib secara kifayah.

Namun hukum fardhu kifayah ini bisa berubah menjadi fardhu 'ain (kewajiban bagi setiap individu tanpa terkecuali), bila daerah yang dihuni Kaum Muslimin (moslems area) mendapat serangan dari luar (baca: 
serangan dari kaum kafir). Seluruh individu Muslim setempat diwajibkan melakukan perlawanan (jihad) atas serangan tersebut, demi mempertahankan diri dan demi menjaga agama dari agitasi lawan, kewajiban ini pernah difatwakan oleh Hadrotus Syaikh KH. Hasyim Asy'ari saat bangsa Indonesia menghadapi agresi belanda dan Inggris di Surabaya.

Hal yang sama juga berlaku dalam hal pemberian bantuan terhadap kawasan Muslim yang mendapat serangan dari musuh, dimana kawasan tersebut hanya berjarak kurang dari masafatul-qashr (jarak dibolehkannya meng-qashar salat). Bagi umat Islam yang berdomisili di kawasan sekitarnya, hukumnya fardlu kifayah memberikan bantuan untuk berjihad bagi saudara-saudaranya yang sedang menghadapi serangan lawan. Hukum fardhu kifayah ini berlaku apabila umat Islam di kawasan yang mendapat serangan itu tidak dalam keadaan terdesak. Artinya mereka masih mampu mengimbangi agresi kaum kafir. Tapi jika mereka sudah dalam keadaan terdesak dan tidak mampu mengimbangi kekuatan musuh, baik dalam hal persenjataan, bahan makanan, dan kwantitas tentara, maka kewajiban berjihad dibebankan kepada seluruh umat Muslim di dunia tanpa terkecuali (fardhu 'ain). ${ }^{23}$

\section{MADZHAB DEFENSIF (DIFA'I) DAN OFENSIF (HUJUM)}

Pada dasarnya kaum muslimin dilarang untuk memerangi kaum kafir. Namun karena umat Islam selalu diteror dan disiksa secara tidak manusiawi, maka Allah memberikan izin dan instruksi jihad kepada kaum Muslimin secara terbatas, yakni hanya sebagai upaya pertahanan diri dari serangan mereka. Setelah fase izin ini, Allah kemudian memerintahkan Kaum Muslimin untuk melakukan jihad fase ketiga, yaitu melalui firman-Nya:

$$
\begin{aligned}
& \text { وقاتلوهم حتى لا تكون فتنة ويكون الدين كله لله فإن انتهوا فلا عدوان } \\
& \text { إلا على الظلمين فإن الله بما يعملون بصير }
\end{aligned}
$$

"Dan perangilah mereka, sehingga tidak ada fitnah lagi, dan (sehingga) agama itu hanya untuk Allah semata. Jika mereka berhenti (memusuhi kamu), maka tidak ada permusuhan (lagi), kecuali terhadap orang-orang zalim. Sesungguhnya Allah Maha mengetahui terhadap apa yang mereka lakukan."(Q.S. al-Baqarah/2: 193).

Menurut al-Qurtubi, terdapat dua pendapat dalam menafsiri ayat ini. Satu versi menyatakan bahwa ayat ini menginstruksikan umat Islam untuk memerangi Kaum Musyrik di manapun mereka berada sampai kemusyrikan 
itu hilang, tanpa harus menunggu adanya agresi dari mereka. Menurut pendapat ini, ayat tersebut telah menganulir (naskh) terhadap ayat-ayat yang menerangkan fase-fase sebelumnya. ${ }^{24}$ Pemahaman inilah yang akhirnya dijadikan landasan oleh sebagian interpreter (mufassirin) dalam memunculkan "Madzhab Jihad Offensif". Pada perkembangan berikutnya, madzhab ini merupakan konsepsi yang menjiwai perjuangan Imam Samudra dan kelompoknya pada khususnya, dan kaum Islam fundamentalis-radikalis pada umumnya.

Sedangkan versi kedua mengatakan, ayat ini tidak menganulir terhadap ayat-ayat yang menerangkan fase-fase sebelumnya. ${ }^{25}$ Artinya, instruksi ini hanya terbatas untuk memerangi kaum kafir yang melakukan agresi, penganiayaan, pemurtadan, dan pendeportasian terhadap kaum Muslim. Versi ini nampaknya merupakan hipotesis-deduktif yang dipakai oleh sebagian ulama untuk membangun "Madzhab Jihad Deffensif". Prinsip dari paham deffensif ini adalah, sebuah peperangan hanya di lakukan dalam rangka untuk mempertahankan diri dari tekanan dalam bentuk apapun yang di lakukan oleh pihak kafir.

\section{KLASIFIKASI PERANG}

Agama apapun memandang bahwa peperangan adalah suatu hal yang buruk karena mengakibatkan jatuhnya korban jiwa dan rusaknya tatanan kehidupan. Namun dampak destruktif tersebut harus di abaikan jika memang kondisi tidak memungkinkan untuk menghindarinya, dengan catatan perang tersebut didasarkan pada tujuan mulia, yaitu untuk dakwah menegakkan ajaran agama. Agama Islam sebagaimana dalam Al-Qur'an tidak melegalisasi peperangan kecuali demi mencapai empat tujuan: ${ }^{26}$ Pertama, memerangi kaum musyrik yang tidak mengindahkan dakwah Islamiyah dan mencoba melawannya, lebih dari itu mereka juga mengintimidasi dengan berbagai siksaan demi membatalkan dakwah Islamiah; kedua, memerangi orang-orang yang merampas hak-hak orang muslim, seperti memerangi pembegal, perampok, dan lain sebagainya; ketiga, memerangi orang-orang murtad, karena mereka di anggap membahayakan agama dengan melakukan tindakan provokasi dan melakukan propaganda. Perang semacam ini pernah di lakukan oleh Abu Bakar al-Sidik sebagai upaya preventif terhadap agama; keempat, memerangi kelompok pemberontak (bhughat) yang menolak untuk taat pada pemerintahan yang sah dan benar, atau melanggar undang-undang dan menolak untuk memenuhi kewajiban sebagai warga negara. Perang 
semacam ini pernah dilakukan oleh Ali Bin Abi Thalib sebagai upaya konservasi terhadap "kesatuan umat Islam". ${ }^{27}$

Peperangan yang disyariatkan dalam Islam dan dipandang sebagai jihad adalah peperangan yang hanya mengandung tujuan-tujuan seperti di atas, sehingga peperangan selain itu hukumnya haram, seperti perang yang dipicu oleh motivasi untuk mendapatkan harta, untuk pamer kekuatan, unjuk keberanian, kesombongan, rasisme (ashabiyah), balas dendam, kecemburuan, rivalitas, atau memperebutkan kedudukan.

Peperangan yang bertujuan negatif adalah tercela dan tidak bisa di kategorikan jiha $>d f i>s a b i>l i l l a>h$. Menurut satu pendapat, tidak semua peperangan bisa disebut jihad. Hanya peperangan yang murni bertujuan untuk menegakkan agama Islam sajalah yang bisa disebut jihad. ${ }^{28}$ Demikan juga jihad akan menjadi tercela jika disertai tujuan mencari harta dan sebagainya, sesuai kandungan hadits:

$$
\text { إن الله لا يقبل من العمل إلا ما كان له خالصا وابتغي به وجهه }
$$

"Sesungguhnya Allah tidak menerima amal-amal kecuali yang bertujuan murni untuk menapat ridha-Nya."(HR. An-Nasa'i). ${ }^{29}$

\section{PENDIDIKAN, JIHAD TERBESAR PESANTREN}

Setelah penulis menelusuri literatur-literatur pesantren salaf, Jihad dalam pengertian sebagai kesungguhan memperjuangkan kebenaran dan menjunjung tinggi ajaran Islam, dalam penerapannya memiliki tiga klasifikasi, yakni (a) amar ma'ruf, (b) pendidikan, dan (c) dakwah Islamiyah. Perang melawan orang kafir tidak disebutkan secara khusus di sini, karena perang sudah masuk dalam kerangka amar ma'ruf.

Dalam pengaplikasiannya, jihad harus dilakukan sesuai dengan prosedur yang telah ditetapkan oleh syariat. Karena jihad yang tidak sesuai dengan aturan syariat akan dikategorikan sebagai bid'ah dhalalah dan pelakunya diancam menjadi penghuni neraka. ${ }^{30}$ Karena itu, penerapan jihad harus selalu mengacu kepada prosedur-prosedur syar'i, sehingga tidak terjebak dalam simbol-simbol belaka tanpa mengetahui hakikat yang sebenarnya.

Dalam masalah jihad, jihad yang paling memungkinkan untuk dilakukan oleh tiap individu di Indonesia adalah jihad perjuangan di dunia pendidikan, karena menurut penulis jalur pendidikan sangat efektif dan menjanjikan dalam mempersiapkan generasi masa depan dalam menyebarkan agama Islam. Terbukti, sejak zaman penjajahan sampai sekarang, kiprah pendidikan sangat mendominasi sejarah perjuangan di 
Indonesia. Banyak alumni-alumni lembaga pendidikan pesantren yang telah berhasil menyebarluaskan ajaran Islam melalui pendidikan, disamping juga berhasil mempertahankan eksistensi akidah Islam dari rongrongan para misionaris salib. Penulis lebih condong terhadap pendidikan karena berpegang pada firman Allah yang berbunyi:

$$
\begin{aligned}
& \text { ومـاكـان المؤمنـون لينفروا كافة فلولا نفـرمن كل فرقـة مـنهم طائفـة ليتفقهوا في } \\
& \text { الدين ولينذروا قومهم إذا رجعوا إليهم لعلهم يحذرون }
\end{aligned}
$$

Tidak sepatutnya orang-orang mukmin pergi semua ke medan perang. Mengapa tidak pergi dari tiap-tiap golongan diantara mereka beberapa orang untuk memperdalam pengetahuan agama dan untuk memberi pengetahuan kepada kaum mereka, bila kelak mereka telah kembali kepada kaumnya, supaya mereka dapat memelihara diri (QS. at-Taubah/9: 122)

Dan firman Allah:

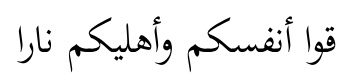

Peliharalah dirimu dan keluargamu dari api neraka. (QS. at-Tahrim/66: 5)

Serta kaidah fiqh:

$$
\text { العمل المتعد افضل من العمل القاصر }
$$

Perbuatan yang manfaatnya bersifat umum lebih baik daripada perbuatan yang manfaatnya terbatas. ${ }^{33}$

Pesantren memandang bahwa jihad dengan pendidikan lebih efektif dan efisien dibandingkan jihad dengan cara lain. Wali Songo mampu menyebarkan Islam hampir di seluruh tanah Jawa, dengan memilih jihad di jalur pendidikan.

\section{JIHAD ADA DIMANA-MANA}

Dari uraian di muka, dapat penulis simpulkan bahwa jihad tidak bisa dimaknai hanya sebatas sebagai peperangan mengangkat senjata, melainkan segala hal yang bisa menegakkan ajaran agama dan bisa mendekatkan diri kepada Allah adalah jihad juga. Untuk lebih rincinya, mari kita kaji makna jihad dari berbagai sisi:

Pertama: pengertian jihad. Jihad merupakan sebuah media untuk 
menegakkan Agama Islam dan sarana untuk mendapat ridha Allah Swt. ${ }^{34}$ Pengertian ini sangat relevan dengan berbagai kondisi dan situasi yang berkembang sekarang. Walaupun dalam beberapa literatur klasik dijelaskan bahwa jihad adalah memerangi orang kafir, namun pengertian itu tidak menafikan pemaknaan terhadap jihad itu sendiri.

Bagi sebagian kalangan, jihad sering diartikan sebagai perang melawan orang kafir. Sebab mereka saat itu memang sedang berhadapan dengan para agresor kafir, seperti di Palestina atau di Irak. Sementara sebagian yang lain mengartikan jihad sebagai dakwah, karena memang mereka sedang berdakwah di tengah-tengah masyarakat yang belum tersentuh ajaran agama. Dan ada pula yang memaknai jihad sebagai perjuangan di bidang pendidikan, karena mereka memang sedang mendidik generasi muda Islam yang akan memperjuangkan agama Islam di masa yang akan datang.

Baik yang memaknai jihad sebagai perang, dakwah, maupun pendidikan, mereka semua memiliki tujuan yang sama. Yaitu untuk menegakkan agama Allah dan untuk menggapai ridha-Nya. Titik.

Namun penulis menentang keras jika terminologi jihad diletakkan tidak pada tempatnya. Banyak sekali penyalahgunaan istilah jihad, sehingga yang terjadi kemudian bukan cuma kesalahpahaman tentang jihad itu sendiri, tapi juga kesalahpahaman terhadap ajaran Islam. Sudah kita maklumi, operasional jihad tidak lepas dari pertimbangan maslahah dan mafsadah, sehingga pemaknaan jihad secara semena-mena justru menjadi bumerang bagi ajaran Islam secara keseluruhan. ${ }^{35}$

Kedua, aplikasi jihad. Banyak cara untuk mengaplikasikan jihad, selama hal itu tidak bertentangan dengan tujuan utama yaitu menegakkan agama Allah, dan dijalankan sesuai prosedur yang telah digariskan al-Quran dan hadits, yaitu dimulai dari fase yang paling rendah dulu. ${ }^{36}$

Selain itu, implementasi jihad juga harus mempertimbangkan situasi dan kondisi, karena hal itu sangat berpengaruh terhadap efektifitas jihad. Walisongo pertama kali berdakwah di tanah Jawa tidak menggunakan kekerasan, melainkan dengan cara halus dan santun, serta bisa menyelami situasi, kondisi, dan kebutuhan masyarakat sebagai objek dakwah. Dengan cara demikian, pengaruh dakwah Wali Songo bisa kita rasakan sampai sekarang.

Ketiga, menjadi mujahid (pejihad) sejati. Bagi penulis, menegakkan syariat Tuhan merupakan tujuan utama dari jihad. Karena itu, peperangan dianggap sebagai perantara (wasilah) untuk sampai pada tujuan utama tersebut. Perang bukanlah tujuan utama dari jihad. Perang adalah jalan terakhir dalam berjihad, karena kekerasan hanya dibolehkan bila ada unsur 
keterpaksaan (darurat) ${ }^{37}$

Syariat mengajarkan seluruh manusia untuk melakukan hal yang maslahah dan mencegah segala bentuk mafsadah ${ }^{38}$ Karena memang inti dari Syariat adalah untuk itu. Sehingga ketika seseorang ingin menjadi manusia yang berjihad, maka ia harus mengetahui mana yang mafsadah dan mana yang maslahah untuk kepentingan agamanya. Bencana akan datang ketika kita tidak mampu untuk membedakan mana yang maslahah dan mana yang mafsadah, sehingga kemungkinan besar kita akan terjerumus dalam jurang kenistaan.

Karena itu, yang terpenting bagi kita sekarang adalah, bagaimana kita bisa mengetahui dan memahami aturan-aturan syariat dengan sebenarbenarnya. Tujuannya agar kita benar-benar mampu melaksanakan jihad yang sejati, bukan hanya jihad secara simbolis. Menurut penulis, itu semua hanya bisa digapai dengan terus belajar dan belajar, dan lembaga pendidikan yang mengajarkan Islam secara kaffah, salah satunya, adalah pesantren.

\section{KESIMPULAN}

Jika dipahami secara seksama, tindakan teror yang dilakukan oleh sebagian kalangan Islam, sebenarnya berawal dari perbedaan pemahaman terhadap ajaran Islam itu sendiri. Perbedaan pemahaman tersebut terutama terkait dengan konsep jihad dan mati syahid. Karena itu, perlu dibedakan di sini antara kalangan Islam yang memahami jihad hanya dengan peperangan (mereka biasanya disebut Islam Garis Keras / Radikalis / Fundamentalis, dll), dengan kalangan Islam yang memaknai jihad itu bisa diwujudkan dalam banyak bentuk, tidak hanya perang saja, seperti kalangan Islam Moderat.

Dalam ajaran Islam, prinsip yang diusung adalah menyebarkan ajaran Islam yang tawasuthi wa manhaji, moderat tapi memiliki dasar kuat. Lembaga pendidikan pesantren yang merupakan lahan penyemaian para ulama, mayoritas berada pada mainstream itu. Ajaran tawasut (moderat), i'tidal (tengah-tengah), tasamuh (santun), dan lain sebagainya, telah menjadi mainstream perjuangan pesantren sejak ratusan tahun yang lalu. Jadi, tuduhan bahwa pesantren merupakan sarang teroris atau penyemaian terorisme, jelas tidak bisa diterima. []

\section{Catatan Akhir:}

* Rustam Ibrahim, M.Ag. adalah Dosen Tetap Universitas Nahdlatul Ulama (UNU) Surakarta, Mahasiswa Program Doktor IAIN Walisongo Semarang. 
1 Abudin Nata, Sejarah Pertumbuhan dan Perkembangan Lembaga- lembaga Pendidikan Islam di Indonesia, (Jakarta : Grasindo, 2001), h. 61.

${ }^{2}$ Wahbah al-Zuhaili, al-Fiqh al-Islami wa 'Adillatuh, (Beirut: Da $>\mathrm{r}$ al-Fikr, 1997), jilid 8, h. 5846.

${ }^{3}$ Dalam konsep ushul fiqh disebutkan, bahwa bila kita menemukan kalimat yang umum digunakan dalam syariat, maka definisinya harus mengikuti terminologi syariat. Jika belum ada definisi dari syariat, maka pengertian tersebut diserahkan pada pendapat publik ('urf al-nas), karena secara dhahir syariat telah memberikan justifikasi hukum terhadap apa yang mereka ketahui. Setelah itu, barulah kemudian didefinisikan secara lughat (etimologi), itupun bila publik tidak mampu menjawabnya. Lihat Badruddin Bin Muhammad Baha $>$ dir az-Zarkasyi $>, B a h\} r$ al-Muh $\} i>t\}$, (Beirut: Da $>$ r al-Kutub, t.th). jilid 5, h. 87.

${ }^{4}$ Ibra $>$ hi $>$ m al-Baju $>$ ri $>$, al-Baju $>r i>$, (Indonesia: Maktabah Dahlan, t.th), Jilid 2, h. 261.

${ }^{5}$ Al-Ghazali, al-Must\}as,fa>, (Beirut: Da $>$ al-Kutub al-Ilmiah, 2000), h. 342.

${ }^{6}$ Al-Ghazali, Ih $\} y a>{ }^{\prime} U l u>m$ ad-Di $>n$, (Kairo: Da $>\mathrm{r}$ al-Kutub al-Isla $>$ miyah, t.th), Juz 2, h 302.

${ }^{7}$ Wahbah al-Zuhaili, al-Fiqh al-Islami, h. 5846.

8 Jamal ad-Di $>$ n as-Suyu $>$ t $\}$ i $>$, Syarh $\}$ Sunan Ibn Ma $>$ jah, editor: Abdul Ghani dan Fakhr al-H \{asan ad-Dahlawi>, (Karachi: Qadim Kutub Khanah, 1999) jilid 1, h 282.

9 Ali Ahmad al-Jurjawi, Hikmat al-Tasyri' wa Filsafatuhu, (Beirut: Da>r al-Fikr, 1997), h. 219.

${ }^{10}$ Orang-orang yang pertama kali mengibarkan panji-panji Islam berjumlah tujuh, yaitu: Nabi SAW, Abu Bakar, Suhaib, Bilal, Khabab, 'Amar, dan Samiyah ibu 'Amar. Beruntung Nabi SAW, mendapatkan perlindungan dari pamannya, Abu Thalib, begitu juga Abu Bakar, ia mendapatkan perlindungan dari kaumnya.

${ }^{11}$ Umar Abdul Jabbar, Khulashah Nur al-Yaqin, (Surabaya: Maktabah Syekh Salim bin Sa'id Nabhan, tth), juz 1, h. 14.

${ }^{12}$ Diceritakan dari Utsman bin Affan ra, bahwa Rasulullah SAW. bersabda kepada keluarga Yasir:

$$
\text { صبرا آل ياسر فإن مصيركم إلى الجنة }
$$

"Bersabarlah wahai keluarga Yasir, sesungguhnya tempat kalian kelak adalah surga." (H.R. Abdul Malik al-Jadi). Lihat antara lain pada; Abu> $\mathrm{Na}$ 'i $>\mathrm{m}$ Ahmad bin Abdulla $>\mathrm{h}$ al-Ashbiha $>$ ni $>$, Hilyah al-Auliya', (Beirut : Dar al-Kutub al-Arabi $>$, 1405), jilid 1, h. 140.

13 Abd al-Hamid, Hawasyi asy-Syarwani, (Lebanon: Da>r al-Kutub al-Ilmiyah, 1996), Jilid 12, h. 5.

${ }^{14}$ Menurut Ali as-S $\}$ abu $>$ ni $>$, karakter orang Arab yang umumnya pembangkang dan tidak sabar untuk membalas tindakan Kafir Kuraisy, sebenarnya sedang diuji oleh 
Allah dengan perintah bersabar. Para sahabat Nabi itu sebenarnya sedang diuji untuk merasakan penderitaan dan mentaati perintah Allah, sehingga terjadi keseimbangan (balance) antara sifat taat dan sifat pembangkang dalam sebuah golongan yang dipersiapkan oleh Allah dalam misi pebyebaran agama Islam di tahun-tahun berikutnya. Artinya, jika ujian itu dapat dilalui dengan baik, maka itu pertanda bahwa watak keras mereka sudah mengendur dan mereka telah siap menjadi pejuang-pejuang agama yang teguh dan pantang mundur.

Sudah sangat maklum, bahwa Umat Islam saat itu hidup berdampingan dengan keluarga mereka yang masih musyrik, sehingga mereka sering mendapat intimidasi dan siksaan yang tiada tara dari keluarga sendiri. Salah satu contohnya adalah upaya orangorang Quraisy untuk mengisolasi salah satu klan mereka sendiri, yakni Bani Hasyim. Pengisolasian terhadap Bani Hasyim itu dilakukan karena Bani Hasyim memberi perlindungan kepada Nabi SAW., sehingga mereka dapat membatasi pergerakan dakwah Nabi SAW. Namun karena melihat keteguhan hati kaum Muslimin, akhirnya orang-orang yang sebelumnya tidak beriman dan keras kepala berubah pikiran dan membebaskan Bani Hasyim, bahkan banyak diantara Kaum Quraisy itu yang bersimpati dan kemudian memeluk agama Islam. Lihat Syaikh M. Ali as\}-S\}abu>ni>, Rawa-i' alBaya $>n$, (Beirut: Dar al-Fikr, t.th), jilid 1, h. 229. 487.

${ }^{15}$ Ima $>\mathrm{m}$ at $\}-$ T\} abari $>$, Tafsi $>$ r at\}-T\}abari $>$, (Beirut: Dar al-Fikr, 1405), Juz 1, h.

${ }^{16}$ Ibid., Juz 14, h. 199.

${ }^{17}$ Umar Abdul Jabbar, Khulashah, h. 49.

${ }_{18}$ Lihat antara lain; Ahmad bin Muhammad Shawi, Hasiyah al-Shawi, Beirut: Darul Kutub al-Ilmiah, t.t. jilid 2, hlm 494: al-Qurtubi, al-Ja>mi' li Ah'kam al-Qur'a>n, (Beirut: Da>r al-Kutub, 1993), jilid 7, h 47: dan Ibn Kasli>r, Tafsi $>r$ al-Qur'a $>n$ al$A z\} i>m$, (Lebanon : Dar al-Fikr, 1992), Jilid 3, h. 275.

${ }^{19}$ Wahbah al-Zuhaili, al-Fiqh al-Islami.

${ }^{21}$ Musthafa Dibb al-Bugha dan Musthafa al-Khin, Fiqh Manhaji, (Damaskus: Dar> al-Qalam, 2000), jilid 3, h. 479.

22 at $\}-$ T abari $>$, Tafsi $>r$, Juz 2, h. 344.

${ }^{23}$ Wahbah al-Zuhaili, al-Fiqh al-Islami, h 5850.

${ }^{24}$ al-Qurt\} ubi, al-Jami', jilid 1, h. 236.

25 Abu Hasan Ali bin Muhammad bin H\}abi $>$ b al-Mawardi $>$, Ah\}kam asSult\}a $>$ niyah, Beirut: Da $>$ r al-Fikr, 1960), h 55.

${ }^{26} \mathrm{Ibid}$, h. 59.

${ }^{27}$ Sementara at $\}-T$ \}abari $>$ dan beberapa ulama lainnya tidak menganggap tercela terhadap jihad yang mengandung tujuan-tujuan lain, dengan catatan, tujuan lain tersebut bukan tujuan utama. Sementara hadits di atas diartikan sebagai tidak diterimanya amal dengan tujuan ganda yang sama-sama utama.

${ }^{28}$ Ahmad bin Syua'ib Abu> Abd ar-Rah\}ma $>n$ an-Nasa $>$ 'i, Sunan an-Nasa>'i", (Khlmab: Maktab Al-Mathbu'at al-Islamiyah, tth), jilid 6, h 25. 
${ }^{29}$ Lihat: "Mausu'ah Fiqhiyah", Kuwait: Wizarat al-Awqaf wa al-Syu'un alQuwaitiyah, jilid 8, h. 23.

32 az-Zarkasyi>, al-Mans|ur, (Beirut: Dar al-Kutub al-Ilmiyah, 2000), jilid 2, h 137.

${ }_{33}$ Wawancara dengan KH. Azizi Hasbullah pada tanggal 16 Juli 2010.

34 Muhammad bin Hibban bin Ahmad Abu Hatim at-Tamimi, al-Tsiqat, Beirut: Dar al-Fikr, jilid 1, hlm 241, Maktabah Alfiyah li al-Sunnah al-Nabawiyah 1999.

${ }^{35}$ Wahbah az-Zuhaili>, Subul al-Istifada (Damaskus: Dar al-Maktabi, 2010), h 15.

${ }^{37}$ Sayid al-Bakri ibn Sayid Muhamad Syat\}a ad-Dimyati $>$, I'anah $\left.a t\right\}-T a>l i b i>n$, (Beirut: Dar al-Fikr, tth). jilid 4, h 172.

$38 \mathrm{Abu}>$ Muhamad Izzudin bin Abd as-Sala $>\mathrm{m}, \mathrm{Q} a w a>$ 'id al-Ahjkam, (Beirut: Muassasah ar-Rayyan, 1990), jilid 1, h 11. 


\section{DAFTAR PUSTAKA}

Abd al-Hamid, Hawasyi asy-Syarwani, (Lebanon: Da $>\mathrm{r}$ al-Kutub al-Ilmiyah, 1996)

ad-Dimyati, Sayid al-Bakri ibn Sayid Muhamad Syat\}a, I'anah at\}Talibin, (Beirut: Dar al-Fikr, tth).

Asbihani, Abu Na'im Ahmad bin Abdullah Hilyah al-Auliya', (Beirut :

Dar al-Kutub al-Arabi, 1405).

az-Zarkasyi, Badruddin Bin Muhammad Bahadir, Bahr al-Muhit, (Beirut: Dar al-Kutub, t.th)

Bajuri, Ibrahim al-Bajuri (Indonesia: Maktabah Dahlan, t.th).

Ghazali, al-Mustasfa, (Beirut: Dar al-Kutub al-Ilmiah, 2000).

Ghazali, Ihya' Ulum ad-Din,(Kairo:Dar al-Kutub al-Islamiyah, t.th)

Ibn Kasir, Tafsir al-Qur'an al-Az\}im, (Lebanon : Dar al-Fikr, 1992).

Imam at\}-T\}abari, Tafsirat-Tabari,(Beirut:Daral-Fikr,1405)

Jabbar, Umar Abdul, Khulashah Nur al-Yaqin, (Surabaya: Maktabah Syekh Salim bin Sa'id Nabhan, th).

Jurjawi, Ali Ahmad, Hikmat al-Tasyri' wa Filsafatuhu, (Beirut: Dar al-Fikr, 1997).

Mawardi, Abu Hasan Ali bin Muh $\}$ ammad bin $\mathrm{H}\}$ abi $>\mathrm{b}$ Ah $\}$ kam as-Sultaniyah, (Beirut: Dar al-Fikr, 1960).

Mustafa Dibb al-Bugha dan Mustafa al-Khin, Fiqh Manhaji, (Damaskus: Dar al-Qalam, 2000).

Nata, Abudin, Sejarah Pertumbuhan dan Perkembangan Lembagalembaga Pendidikan Islam di Indonesia, (Jakarta : Grasindo, 2001).

Qurtubi, al-Jami' li Ah\}kam al-Qur'an, (Beirut: Dar al-Kutub, 1993).

Sabuni, Syaikh M. Ali Rawa-i' al-Bayan, (Beirut: Dar al-Fikr, t.th).

Sawi, Ahmad bin Muhammad Hasiyah al-Shawi, (Beirut: Darul Kutub al-Ilmiah, t.th).

Suyuti, Jamal ad-Din Syarh Sunan Ibn Majah, editor: Abdul Ghani dan Fakhr al-Hasan ad-Dahlawi, (Karachi: Qadim Kutub Khanah, 1999).

Zarkasyi, al-Manslur, (Beirut: Dar al-Kutub al-Ilmiyah, 2000)

Zuhaili, Wahbah, al-Fiqh al-Islami wa 'Adillatuh, (Beirut: Dar alFikr, 1997

Zuhaili, Wahbah, Subul al-Istifadah, (Damaskus: Da $>\mathrm{r}$ alMaktabi,2010). 